\title{
A newly recognized 13q12.3 microdeletion syndrome characterized by intellectual disability, microcephaly, and eczema/atopic dermatitis encompassing the HMGB1 and KATNAL1 genes
}

\author{
Bartholdi, Deborah ; Stray-Pedersen, Asbjørg ; Azzarello-Burri, Silvia ; Kibaek, Maria ; Kirchhoff, \\ Maria ; Oneda, Beatrice ; Rødningen, Olaug ; Schmitt-Mechelke, Thomas ; Rauch, Anita ; Kjaergaard, \\ Susanne
}

\begin{abstract}
Proximal deletions of the long arm of chromosome 13 have been reported only rarely. Here we present three unrelated patients with heterozygous, apparently de novo deletions encompassing 13q12.3. The patients present with moderate demonstrated or apparent intellectual disability, postnatal microcephaly, and eczema/atopic dermatitis as the predominant symptoms. In addition, they had pronounced feeding difficulties in early infancy. They displayed similar facial features such as malar flattening, a prominent nose with underdeveloped alae nasi, a smooth philtrum, and a thin vermillion of the upper lip. The proximal and distal breakpoints were clustered and the deletions spanned from 1.4 to $1.7 \mathrm{Mb}$, comprising at least 11 RefSeq genes. However, heterozygous deletions partially overlapping those observed in the present patients have been described in healthy parents of patients with Peters-Plus syndrome, an autosomal recessive disorder caused by inactivation of the B3GALTL gene. We therefore propose that the critical region of the 13q12.3 microdeletion syndrome contains only three genes, namely, KATNAL1, HMGB1, and LINC00426, a non-protein coding RNA. The KATNAL1 protein belongs to a family of microtubule severing enzymes that have been implicated in CNS plasticity in experimental models, but little is known about its function in humans. The HMGB1 protein is an evolutionarily conserved chromatin-associated protein involved in many biologically important processes. In summary, we propose that microdeletion 13q12.3 represents a novel clinically recognizable condition and that the microtubule severing gene KATNAL1 and the chromatin-associated gene HMGB1 are candidate genes for intellectual disability inherited in an autosomal dominant pattern.
\end{abstract}

DOI: https://doi.org/10.1002/ajmg.a.36439

Posted at the Zurich Open Repository and Archive, University of Zurich

ZORA URL: https://doi.org/10.5167/uzh-99949

Journal Article

Published Version

Originally published at:

Bartholdi, Deborah; Stray-Pedersen, Asbjørg; Azzarello-Burri, Silvia; Kibaek, Maria; Kirchhoff, Maria; Oneda, Beatrice; Rødningen, Olaug; Schmitt-Mechelke, Thomas; Rauch, Anita; Kjaergaard, Susanne (2014). A newly recognized 13q12.3 microdeletion syndrome characterized by intellectual disability, microcephaly, and eczema/atopic dermatitis encompassing the HMGB1 and KATNAL1 genes. American Journal of Medical Genetics. Part A, 164A(5):1277-1283.

DOI: https://doi.org/10.1002/ajmg.a.36439 


\title{
A Newly Recognized 13q12.3 Microdeletion Syndrome Characterized by Intellectual Disability, Microcephaly, and Eczema/Atopic Dermatitis Encompassing the HMGB1 and KATNAL1 Genes
}

\section{Deborah Bartholdi, ${ }^{1 *}$ Asbjerg Stray-Pedersen, ${ }^{2,3}$ Silvia Azzarello-Burri, ${ }^{1}$ Maria Kibaek, ${ }^{4}$ Maria Kirchhoff, ${ }^{5}$ Beatrice Oneda, ${ }^{1}$ Olaug Rodningen, ${ }^{2}$ Thomas Schmitt-Mechelke, ${ }^{6}$ Anita Rauch, ${ }^{1}$ and Susanne Kjaergaard ${ }^{5}$}

\author{
${ }^{1}$ Institute of Medical Genetics, University of Zürich, Zurich, Switzerland \\ ${ }^{2}$ Department of Medical Genetics, Oslo University Hospital, Oslo, Norway \\ ${ }^{3}$ Molecular and Human Genetics, Baylor College of Medicine, Houston, Texas \\ ${ }^{4}$ Department of Pediatrics, Odense University Hospital, Odense, Denmark \\ ${ }^{5}$ Department of Clinical Genetics, University Hospital of Copenhagen, Rigshospitalet, Copenhagen, Denmark \\ ${ }^{6}$ Pediatric Neurology, Children's Hospital, Lucerne, Switzerland
}

Manuscript Received: 20 April 2013; Manuscript Accepted: 29 December 2013

Proximal deletions of the long arm of chromosome 13 have been reported only rarely. Here we present three unrelated patients with heterozygous, apparently de novo deletions encompassing 13q12.3. The patients present with moderate demonstrated or apparent intellectual disability, postnatal microcephaly, and eczema/atopic dermatitis as the predominant symptoms. In addition, they had pronounced feeding difficulties in early infancy. They displayed similar facial features such as malar flattening, a prominent nose with underdeveloped alae nasi, a smooth philtrum, and a thin vermillion of the upper lip. The proximal and distal breakpoints were clustered and the deletions spanned from 1.4 to $1.7 \mathrm{Mb}$, comprising at least $11 \mathrm{RefSeq}$ genes. However, heterozygous deletions partially overlapping those observed in the present patients have been described in healthy parents of patients with Peters-Plus syndrome, an autosomal recessive disorder caused by inactivation of the B3GALTL gene. We therefore propose that the critical region of the 13q12.3 microdeletion syndrome contains only three genes, namely, KATNAL1, HMGB1, and LINC00426, a non-protein coding RNA. The KATNAL1 protein belongs to a family of microtubule severing enzymes that have been implicated in CNS plasticity in experimental models, but little is known about its function in humans. The HMGB1 protein is an evolutionarily conserved chromatin-associated protein involved in many biologically important processes. In summary, we propose that microdeletion 13q12.3 represents a novel clinically recognizable condition and that the microtubule severing gene KATNAL1 and the chromatin-associated gene $H M G B 1$ are candidate genes for intellectual disability inherited in an autosomal dominant pattern. $\odot 2014$ Wiley Periodicals, Inc.

Key words: microdeletion 13q12.3; KATNAL1; HMGB1; intellectual disability; microarray analysis
How to Cite this Article:

Bartholdi D, Stray-Pedersen A, AzzarelloBurri S, Kibaek M, Kirchhoff M, Oneda B, Rødningen O, Schmitt-Mechelke T, Rauch A, Kjaergaard S. 2014. A newly recognized 13q12.3 microdeletion syndrome characterized by intellectual disability, microcephaly, and eczema/atopic dermatitis encompassing the HMGB1 and KATNAL1 genes.

Am J Med Genet Part A 164A:1277-1283.

Deborah Bartholdi and Asbjørg Stray-Pedersen contributed equally to this work.

The authors declare no conflicts of interest.

Grant sponsor: Swiss National Science Foundation; Grant number: SNF 320030_135669.

${ }^{*}$ Correspondence to: Deborah Bartholdi, M.D., Institute of Clinical Genetics, Klinikum Stuttgart, Bismarckstrasse 3, 70176 Stuttgart, Germany.

E-mail: deborah.bartholdi@usb.ch

Article first published online in Wiley Online Library

(wileyonlinelibrary.com): 24 March 2014

DOI 10.1002/ajmg.a.36439 


\section{INTRODUCTION}

Over the past years it has become apparent that chromosomal rearrangements below the detection level of conventional karyotyping are a common cause of intellectual disability (ID), accounting for up to $15 \%$ of unselected patients with ID [Miller et al., 2010; Vissers et al., 2010]. However, the interpretation with regard to the clinical significance of non-recurrent variants can be challenging and the scientific insight gained from individual patients is often limited. The collection of clinical and genetic information in databases such as DECIPHER allows the identification of unrelated patients with overlapping microdeletions/-duplications, thus helping to establish causality, determine genotype/phenotype correlation and enable the identification of novel disease-causative genes. Using a joint collaborative effort through the DECIPHER database, we present three unrelated patients carrying overlapping submicroscopic deletions at chromosome band 13q12.1-3.

Chromosome 13 has one of the lowest gene densities among human chromosomes and interstitial deletions of $13 \mathrm{q}$ have only rarely been reported by standard karyotyping or microarray analysis [Drummond-Borg et al., 2002; Ballarati et al., 2007; Der Kaloustian et al., 2011; Cirillo et al., 2012].

Here, we present three patients with overlapping heterozygous deletions at 13q12.1-3 with a recognizable phenotype characterized by demonstrated or apparent ID, postnatal microcephaly, and eczema/atopic dermatitis as the predominant symptoms. In addition, all three patients displayed characteristic facial features. This phenotype is associated with a $\sim 300 \mathrm{~kb}$ critical region harboring only three genes, namely KATNAL1, HMG, and the non-protein coding RNA LINC00426.

\section{CLINICAL REPORTS}

Patient 1, a boy, was born at 42 weeks of gestation after an uneventful pregnancy by cesarean to healthy parents of Caucasian origin. Birth weight was 3,200 g (10-25th centile) and length $48 \mathrm{~cm}$ (3rd-10th centile). The OFC was not recorded at birth but was $42 \mathrm{~cm}$ ( 10th centile) at the age of 6 months. He experienced frequent screaming spells in the first months and severe feeding difficulties with recurrent vomiting until the age of $2 \frac{1}{2} 2$ years. $\mathrm{He}$ needed surgery for right-sided undescended testis and bilateral hip dysplasia. A lingual frenulum was cut at the age of 3 years. Motor milestones were within normal limits (sitting at the age of 6 months, walking at 15 months) but language development was delayed (first words at the age of $3 \frac{1}{2}$ years). Assessment of cognitive abilities at the age of 7 years showed an IQ of 53 with subtest values between 50 and 60. He displayed behavioral problems with hyperactivity and hair pulling. An eye examination showed hypermetropia. He developed atopic dermatitis, multiple food allergies, and allergic rhinitis. On examination at the age of 18 years height was $165.5 \mathrm{~cm}(3 \mathrm{rd}-10 \mathrm{th}$ centile), weight $66 \mathrm{~kg}$ (25th-50th centile), and OFC $53 \mathrm{~cm}$ $(-2.5 \mathrm{SD})$. He had eczema on the hands, elbows, and knees and several café au lait spots on the torso. Hands were small and feet short. Truncal obesity and small testes were noted. The facial features are depicted in Figures 1A,D and 2A. Note the short palpebral fissures, fullness of upper eyelids, malar flattening, prominent nose with low insertion of the columella, underdeveloped alae nasi, and thin vermillion of the upper lip.
Patient 2, the girl was delivered by cesarean at gestational age 37 weeks due to intrauterine growth retardation. Birth weight was $2,100 \mathrm{~g}$ ( $3 \mathrm{rd}-10$ th centile), length $47 \mathrm{~cm}$ ( $\sim 25$ th centile), and OFC $32 \mathrm{~cm}$ ( $\sim 25$ th centile). Her APGAR scores were 9/1, 10/5. Redundant nuchal skin, a wide mouth, and a pointed chin were noted at birth. During infancy feeding difficulties and failure to thrive were prominent as well as recurrent vomiting, recurrent upper airway infections and asthmatic bronchitis. At age 18 months she was diagnosed with a diaphragmatic hernia that was surgically corrected. Nevertheless, failure to thrive (height $-3 \mathrm{SD}$ and weight $-3 \mathrm{SD}$ ) and recurrent vomiting continued. From around age 3 years her growth parameters gradually increased to normal except for the OFC. Measurements at the age of 12 years were height $149 \mathrm{~cm}$ (25th-50th centile), weight $39 \mathrm{~kg}$ (25th-50th centile), and OFC $49 \mathrm{~cm}(-2.5 \mathrm{SD})$.

Gross motor milestones were within normal limits (sitting at age 6 months, walking at age 14 months), but speech development was delayed (20 words at age 3 years). She had general hypotonia, decreased balance and stability, and severe constipation, but extensive gastroenterological examinations have been normal. She also suffered from severe atopic dermatitis but no allergies have been documented. Furthermore, at age $3 \frac{1}{2} 2$ years, thoracic kyphoscoliosis and bilateral hypermetropia $(+8)$ became evident. Hearing was normal. Her facial features are shown in Figures 1B,E and 2B. Note fullness of the upper eyelids, malar flattening, a broad nasal tip, underdeveloped alae nasi, a smooth philtrum, a thin vermillion of the upper lip, dental crowding, and a pointed chin.

A cerebral MRI was performed at the age 9 years due to headache and vomiting with normal result. She was attending a school for special needs and was able to read simple texts. The IQ was 54 assessed at the age of 9 years.

Patient 3, a girl, was delivered by forceps-assisted vaginal delivery at gestational age 36 weeks. She was small for gestational age with a birth weight of $1,940 \mathrm{~g}$ ( $<3 \mathrm{rd}$ centile), length $38 \mathrm{~cm}(<3 \mathrm{rd}$ centile), and OFC $32 \mathrm{~cm}$ (25th-50th centile). Her APGAR scores were $6 / 1,7 / 5$, and $8 / 10$. The umbilical cord was noted to be short. She suffered from episodes of apnea that continued after the newborn period, and displayed feeding difficulties with recurrent vomiting. Gastro-esophageal reflux was treated until 2 years of age. At 12.5 years (last examination) she still had feeding difficulties, received supplemental nutrition, and suffered from chronic constipation. She had short stature and was slender (height $130 \mathrm{~cm}$, corresponding to $-3 \mathrm{SD}$, weight $22 \mathrm{~kg}$, corresponding to $-2.8 \mathrm{SD}$ ) but showed disproportionately increased abdominal circumference. She had normal OFC at birth, but developed postnatal microcephaly. Her OFC at 12.5 years was $49.5 \mathrm{~cm}(-2.5 \mathrm{SD})$. She walked at 17 months of age. Her speech was delayed, and she first started to speak in sentences at 5 years. No formal IQ testing was performed but evaluation at the age of 12.5 years showed apparent moderate intellectual disability with an estimated IQ between 40 and 50. A cerebral MRI scan at the age of 3 years was normal. She had chronic secretory otitis media since 2-3 months of age, and underwent 30 tube-operations in total. Anesthesia induced severe postoperative respiratory distress. She had obstructive sleep apnea requiring continuous positive airway pressure therapy at night. Plastic surgery for nasal septum deviation reduced the apnea episodes. She had persistent hearing loss of the 

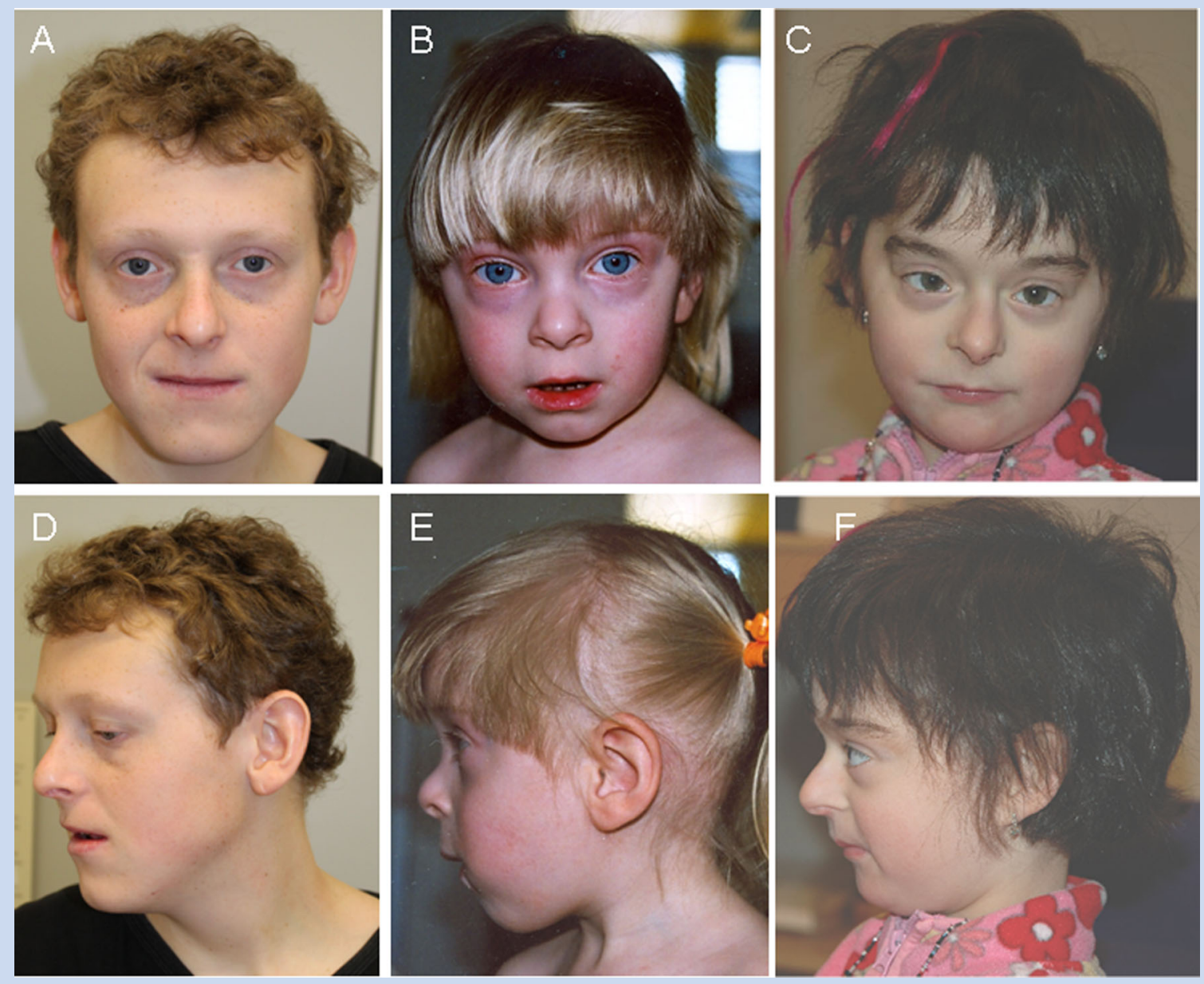

FIG. 1. Facial features of patient 1 (A, D) at the age 18 years, patient 2 [B, E] at the age of $3^{\frac{1}{2} 2}$ years, and patient 3 (C, F] at the age of 9 years. Note similar facial features with fullness of upper eyelids, malar flattening, low insertion of the columella, underdeveloped alae nasi, and a thin vermillion of the upper lip.

left ear and hearing impairment on the right ear, and used hearing devices. She had hypermetropia $(+6)$ and strabismus. Her distinct facial features included malar flattening, fullness of the upper eyelids with ptosis, narrow forehead, a broad and slightly deviated nasal tip, and underdeveloped alae nasi (Fig. 1C,F). Other features included micrognathia, crowded teeth, oligodontia, enamel erosions, and a high palate.

She had hypotonia, and the large joints were hyper extensible, while other joints were stiff and enlarged. She had low muscle endurance and reduced balance. She showed camptodactyly, prominent digit pads, broad fingertips, pes planus, and long great toes. Her right leg was longer than the left. Her progressive bilateral metatarsus adductus made it painful for her to walk, and she underwent orthopedic surgery on both feet at 13 years of age. She had hirsuitism on her back and lower extremities, but her hair and nails were growing slowly and her brittle nails never needed to be trimmed. She had eczema/atopic dermatitis but was not suffering from allergies. She had behavioral problems with hyperactivity and self-mutilation (hair pulling and finger-biting) and temper tantrums. She was said to have good long-term memory, but reduced short-term memory. She was attracted by water and had increased sensitivity to bright lights and sudden sounds. She had tactile aversion as a newborn, and had a strikingly reduced sensitivity to pain.

\section{MATERIALS AND METHODS}

The three patients were all referred to their respective centers in Switzerland, Norway, and Denmark for evaluation of developmental delay. Blood samples were taken from the patients and their parents after informed consent had been obtained.

\section{Conventional Karyotyping and Microarray \\ Analysis}

Karyotyping of G-banded metaphase chromosomes was performed on cultured lymphocytes using standard procedures. Microarray analysis was conducted using different platforms. 

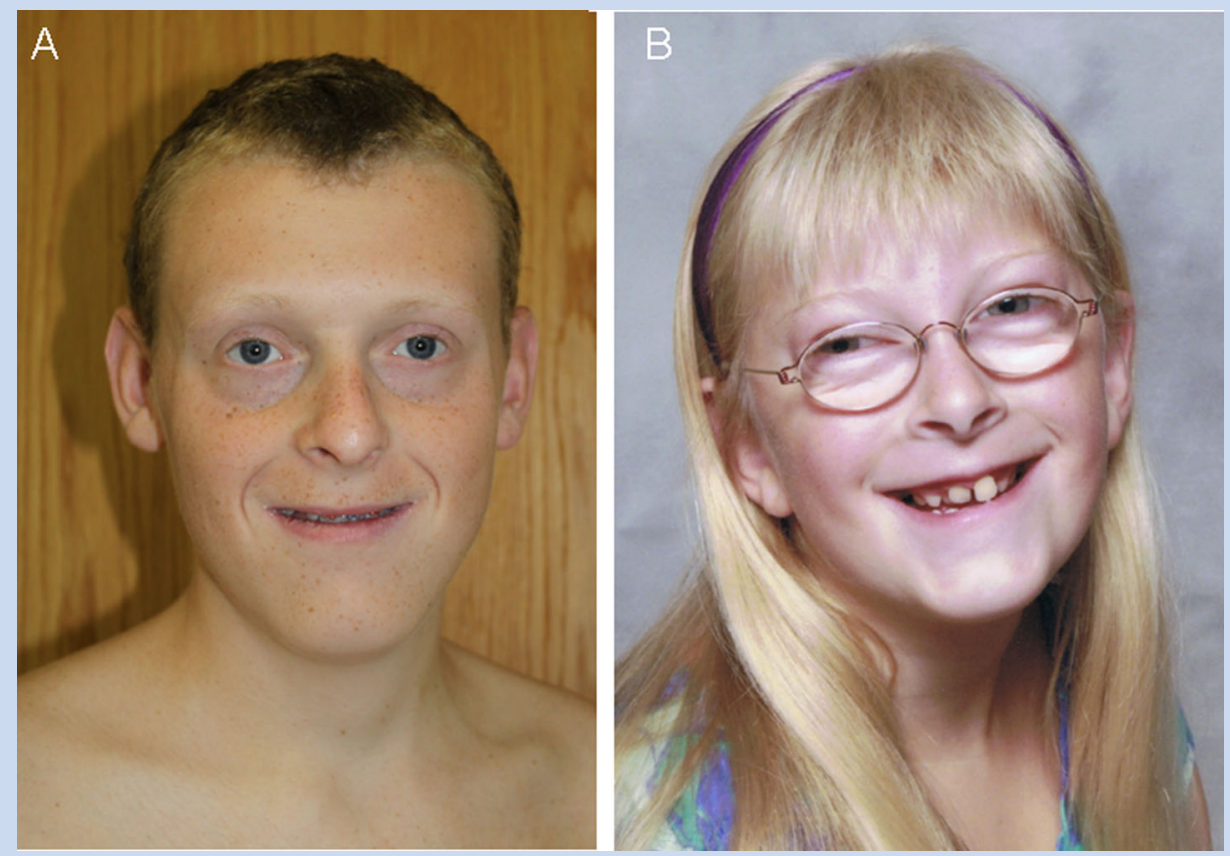

FIG. 2. Patient 1 (A) at the age 20 years and patient 2 (B) at the age of 13 years. Note malar flattening, low insertion of the columella, underdeveloped alae nasi, and similar facial expression.

Patient 1 was analyzed using the Affymetrix Cytogenetics $2.7 \mathrm{M}$ array (Affymetrix, Santa Clara, CA). This platform provides whole genome coverage with 400,000 SNPs and $2.3 \mathrm{M}$ copy number markers. Patient 2 was analyzed with the Agilent CGH $244 \mathrm{~K}$ array (Agilent Technologies, Inc., Santa Clara, CA), and patient 3 with the Agilent CGH $105 \mathrm{~K}$ array. The different arrays were performed according to the respective manufacturer's instructions. The genomic positions of the deletions were mapped to the GRCh37/19 built, assembly Feb 2009. The deletions were confirmed using different methods (see Results section). Analysis of parental samples was performed but biologic parentage was not tested.

\section{RESULTS}

Conventional chromosome analysis did not show structural rearrangements in any of the patients. In all patients an interstitial heterozygous deletion involving chromosomal band 13q12 was identified by microarray analysis (Fig. 3). Patient 1 had an apparently de novo deletion of about $1.58 \mathrm{Mb}$ on 13q12.3 not detectable in the parents and a second deletion of $2.5 \mathrm{Mb}$ on $8 \mathrm{p} 22$ inherited from the healthy father $(\operatorname{arr}[\mathrm{hg} 19] \mathrm{8p} 22(16,513,831-19,023,017)$ x1pat, 13q12.3(30,880,255-32,462,466)x1). The 13q12 deletion was confirmed using FISH probes RP11-550P23 and RP11367C11. Analysis of patient 2 showed an apparently de novo deletion of 1.4 Mb (arr[hg19] 13q12.3(30,760,696x2,30,768,420$32,166,016 \times 1,32,192,734 \times 2)$ ) not present in the parental samples which was confirmed by qPCR. Patient 3 had an apparently de novo deletion of 1.73 Mb on 13q12.3 ( $\operatorname{arr}[\mathrm{hg} 19]$ 13q12.3 (30,781,984x2,
$30,805,425-32,533,892 \times 1,32,582,281 \times 2)$ ) not detected in the parents.

\section{DISCUSSION}

Intellectual disability comprises a group of genetically and phenotypically heterogeneous entities and represents a major diagnostic challenge in clinical genetics. Here we present three unrelated patients with demonstrated or apparent ID with heterozygous deletions encompassing 13q12.3 who have been identified through the DECPHER database. Apart from moderate ID they manifested postnatal microcephaly, eczema/atopic dermatitis, and dysmorphic features. In addition, they had pronounced feeding difficulties in infancy. While motor development was more or less within normal limits, speech acquisition was delayed in all three patients and they displayed behavioral problems such as hyperactivity, selfmutilation, and reduced sensitivity to pain. Other features were hypermetropia $3 / 3$, oligodontia $2 / 3$, recurrent upper airway respiratory infections $2 / 3$, and truncal obesity $2 / 3$. Some features, including diaphragmatic hernia, kyphoscoliosis, unequal leg length, sleep apnea, and multiple food allergies, were observed in one individual only. The three patients shared strikingly similar facial features such as malar flattening, a prominent nose with underdeveloped alae nasi, and a thin vermillion of the upper lip (Table I and Figs. 1 and 2).

The breakpoints were clustered and the deletions spanned from 1.4 to $1.73 \mathrm{Mb}$, comprising at least 11 RefSeq genes (Fig. 3). Due to the use of different microarray platforms it cannot be determined if the proximal breakpoint was the same in all three patients. Het- 


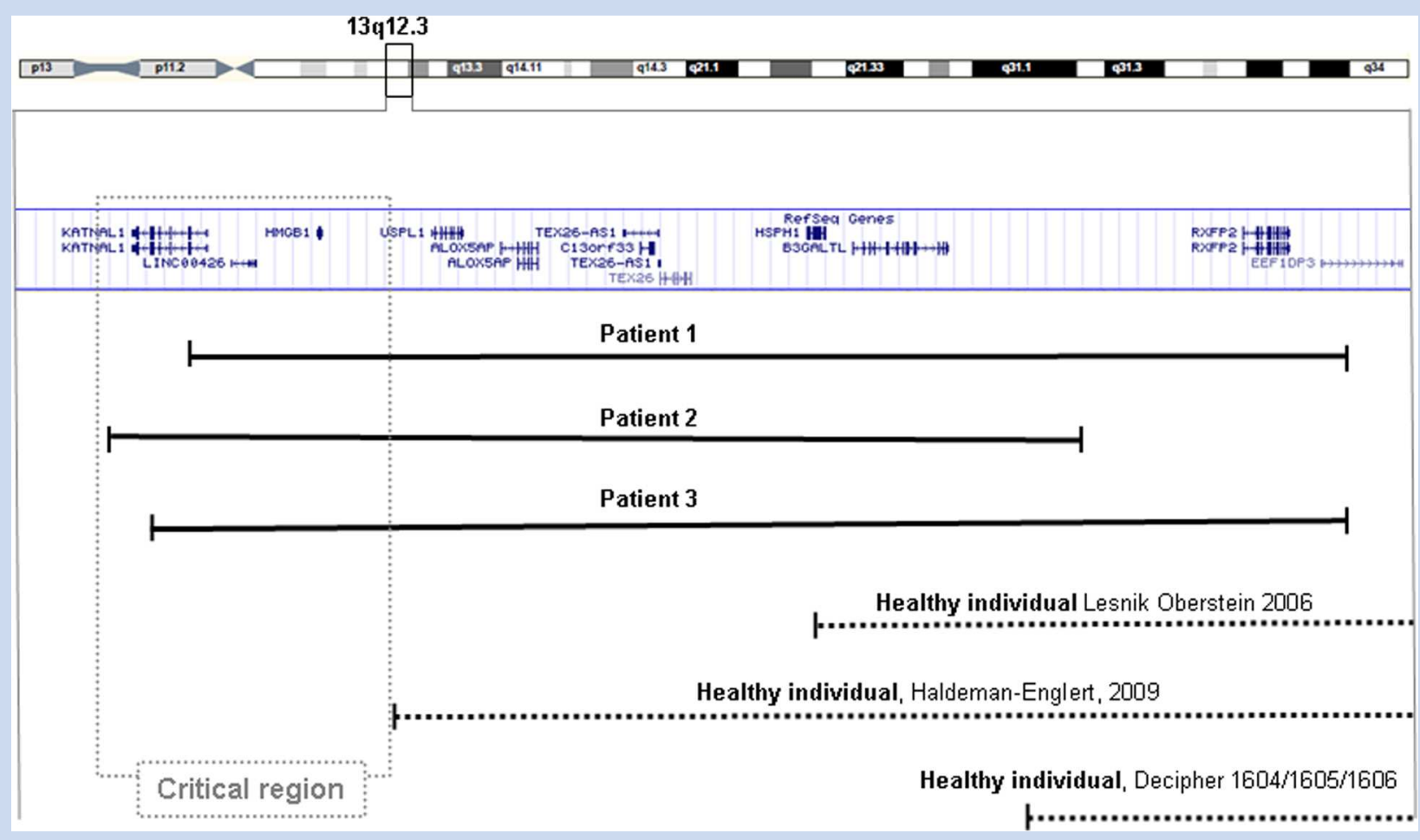

FIG. 3. Map of the 13q12.3 locus. The deletions of the three patients reported here [continuous lines] are compared to those of healthy heterozygotes [dashed lines] reported in the literature [Lesnik Oberstein et al., 2006; Haldeman-Englert et al., 2009] and healthy individuals from the DECIPHER database [\#1604/\#1605/\#1606]. The critical region, indicated by the dashed square, is about $300 \mathrm{~kb}$ in size and contains the genes KATNAL1, LINCO042, and HMGB1. Array data were uploaded into the UCSC Genome Browser, GRCh37/19 build, assembly Feb 2009 [http://www.genome.ucsc.edu].

erozygous deletions partially overlapping those observed in the patients reported here have been described in healthy parents of patients with Peters-Plus syndrome, an autosomal recessive disorder caused by inactivation of the B3GALTL gene [Lesnik Oberstein et al., 2006; Haldeman-Englert et al., 2009]. We therefore propose that the critical region of the 13q12.3 microdeletion syndrome contains only three genes, namely, KATNAL1, HMGB1, and LINC00426.

The LINC00426 (long intergenic non-protein coding RNA 426) transcript is a non-coding RNA of unknown function. Whether haploinsufficiency of this gene causes or contributes to the phenotype remains open.

The second gene in the critical region is KATNAL1 (KATANIN p60 subunit A-like 1), which codes for a recently identified ATPase with high sequence similarity to KATANIN p60 (KATNA1), a member of the microtubule-severing enzyme family. Microtubules are dynamic cytoskeletal polymers that play important roles in cell division, morphogenesis, mobility, and signaling. The remodeling of microtubules is mediated by microtubule-severing enzymes [Sharp and Ross, 2012]. The KATANIN protein exists as a heterodimer of a $60-\mathrm{kDa}$ catalytic subunit (p60, KATNA1) and a 80-kDa targeting and regulatory subunit (p80, KATNB1) [McNally and Vale, 1993]. Katanin and Katanin-like proteins are highly expressed in the nervous system of diverse organisms [de Moor et al., 2012]. A neuronal function for katanin was first demonstrated in cultured rat neurons where it was shown to stimulate axonal outgrowth and establish neuronal polarity [Ahmad et al., 1999; Yu et al., 2005]. Knowledge of the role of the katanin like proteins is still limited. Recently, however, de novo mutations in KATNAL2 (KATANIN p60 subunit A-like 2), a close family member of KATNAL1 (the gene deleted in the patients reported here) have been identified in patients with autism spectrum disorders by exome sequencing [Neale et al., 2012; Sanders et al., 2012].

The third gene located in the critical deletion interval is $H M G B 1$ (High-Mobility Group Box 1) which belongs to the HMG-box family. The HMGB proteins are nuclear proteins, comprised of two DNA-binding domains (HMG boxes A and B) and an acidic tail, which seems to have a regulatory function in DNA-binding. The HMGB1 protein is widely expressed in all tissues of vertebrates and is the most abundant non-histone protein in the nucleus [Bianchi and Beltrame, 1998]. It is engaged in numerous nuclear processes such as transcription, replication, recombination, and repair. The importance of $H M G B 1$ is reflected by the fact that homozygous knock out mice die shortly after birth, very likely due to inefficient activation of glucocorticoid receptor responsive genes [Calogero et al., 1999]. Apart from its role as a nuclear chromatin-associated protein, HMGB1 is released in the extracellular environment inducing secretion of proinflammatory cytokines [Lotze and 


\section{TABLE I. Comparison of Clinical Features}

Size of deletion

Platform

Gender, age at report (years)

Height $(\mathrm{cm})$

Weight $(\mathrm{kg})$

OFC $(\mathrm{cm})$

Pregnancy, IUGR

Gestational age (weeks)/mode

of delivery

Birth weight $(\mathrm{g})$

Birth length $(\mathrm{cm})$

OFC at birth $(\mathrm{cm})$

Recurrent vomiting

Failure to thrive

Constipation

Fullness of upper eyelids

Malar flattening

Underdeveloped alae nasi

Low insertion columella

Thin vermillion upper lip

Atopic dermatitis

Hypermetropia

Oligodontia

Camptodactyly

Other features

Age at walking (months)

Language delay

Intellectual disability, 10

Hyperactive

Self mutilation

Reduced sensitivity to pain
Patient 1

$1.58 \mathrm{Mb}$

Affymetrix 2.? Cytoscan

male, 19

165.5 (3rd-10th centile)

$66\left(25^{\text {th }}-50^{\text {th }}\right.$ centile $)$

53 (-2.5 SD)

$+$

42, cesarean

3,200 (10th-25th centile)

48 (3rd-10th centile)

$\mathrm{nr}$

$+$

$+$

$+$

$+$

$+$

$+$

$+$

$+$

$+$

$+$

$+$

Cryptorchidism,

hip dysplasia,

multiple food

allergies, obesity

\author{
Patient 2 \\ $1.4 \mathrm{Mb}$ \\ Agilent $244 \mathrm{k}$ \\ female, 12 \\ 149 (25th-50th centile) \\ $39\left(25^{\text {th }}-50^{\text {th }}\right.$ centile $)$ \\ 49.5 (-2.5 SD) \\ $+$ \\ 37, cesarean
}

\section{2,100 (3rd-10th centile) \\ 47 (25th centile) \\ 32 (25th centile)}

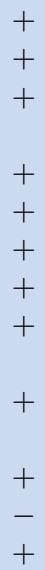

Diaphragmatic hernia, kyphoscoliosis, recurrent airway infections, obesity

15

$+$

53

$+$

$+$

$+$
14

$+$

54

$+$

IUGR, intrauterine growth retardation; $\mathrm{m}$, months; $\mathrm{nr}$, not recorded; SD, standard deviation.

Patient 3

$1.73 \mathrm{Mb}$

Agilent $105 \mathrm{k}$

female, 12.5

$130(-3 \mathrm{SD})$

$22(-2.8 \mathrm{SD})$

$49.5(-2.5 \mathrm{SD})$

$+$

36 , forceps

$1,940(<3$ rd centile $)$

$38(<3$ rd centile $)$

32 (25th-50th centile)

$+$

$+$

$+$

$+$

$+$

$+$

$+$

$+$

$+$

$+$

$+$

$+$

Chronic otitis, hearing loss, obstructive sleep apnea, recurrent airway infections, asymmetry legs

17

$+$

Estimated 40-50

+
+
+
Tracey, 2005]. Accordingly, it plays an important role in various conditions, such as sepsis, rheumatoid arthritis, hemorrhagic shock, ischemia-reperfusion injury, and invasive tumor growth. With regard to the central nervous system, HMGB1 (which is identical to the neurite outgrowth-promoting protein $\mathrm{p} 30$, amphoterin and SBP-1) displays a complex temporal and spatial expression pattern during early brain development. It promotes neurite outgrowth and cell migration in rat brain and is critical for forebrain development [reviewed in Fang et al., 2012]. In adulthood, its expression is down regulated in the majority of neurons.

For the patients reported here, haploinsufficiency of all three RefSeqgenes present in the critical region might potentially cause or contribute to the ID. The HMGB1 gene is a likely candidate, since the control of gene transcription through epigenetic modification of the chromatin structure in neurons has been shown to play an important role in cognitive processes and in the etiology of ID [van Bokhoven, 2011]. Other examples of ID genes acting in the epigenetic control of gene transcription are the genes for Kleefstra syndrome (EHMT1) and Rubinstein-Taybi syndrome (CREBBP and EP300). Furthermore, HMGB1 and closely related family members of KATNAL1 have been implicated in regulation of neurite outgrowth, which is consistent with the observation that many ID-genes are involved in synaptic plasticity. The role of KATNAL1 in causing ID is also supported by the recent observation 
that mutations in its family member KATNAL2 are a cause of nonsyndromic ID/autistic spectrum disorders [Neale et al., 2012; Sanders et al., 2012].

In conclusion, we report an example of reverse phenotyping by describing three patients carrying nearly identical heterozygous deletions of 13q12.3 and sharing a similar and recognizable phenotype. The critical region encompasses only three genes. For two of them, the microtubule-severing enzyme KATNAL1 and the chromatin-associated protein $H M G B 1$, current knowledge qualifies them as candidate genes for autosomal dominant ID. The future identification of patients carrying point mutations would confirm this hypothesis and help increase our knowledge of the complex molecular pathways causing ID.

\section{ACKNOWLEDGMENTS}

We are grateful to the patients, their parents and the treating physicians for collaboration. This study was enabled by a collaborative effort through the DECIPHER database (Database of Chromosomal Imbalance and Phenotype in Humans using Ensemble Resources). A full list of centers that contributed to the generation of the data is available from http://decipher.sanger.ac.uk. A. R. was supported by a grant from the Swiss National Science Foundation (SNF 320030_135669).

\section{REFERENCES}

Ahmad FJ, Yu W, McNally FJ, Baas PW. 1999. An essential role for katanin in severing microtubules in the neuron. J Cell Biol 145:305-315.

Ballarati L, Rossi E, Bonati MT, Gimelli S, Maraschio P, Finelli P, Giglio S, Lapi E, Bedeschi MF, Guerneri S, Arrigo G, Patricelli MG, Mattina T, Guzzardi O, Pecile V, Police A, Scarano G, Larizza L, Zuffardi O, Giardino D. 2007. 13q Deletion and central nervous system anomalies: Further insights from karyotype-phenotype analyses of 14 patients. J Med Genet 44:e60.

Bianchi ME, Beltrame M. 1998. Flexing DNA: HMG-box proteins and their partners. Am J Hum Genet 63:1573-1577.

Calogero S, Grassi F, Aguzzi A, Voigtländer T, Ferrier P, Ferrari S, Bianchi ME. 1999. The lack of chromosomal protein Hmg1 does not disrupt cell growth but causes lethal hypoglycaemia in newborn mice. Nat Genet $22: 276-280$.

Cirillo E, Romano R, Romano A, Giardino G, Durandy A, Nitsch L, Genesio R, Di Gregorio E, Cavalieri S, Abate G, Del Vecchio L, Brusco A, Pignata C. 2012. De novo 13q12.3-q14.11 deletion involving BRCA2 gene in a patient with developmental delay, elevated IgM levels, transient ataxia, and cerebellar hypoplasia, mimicking an A-T like phenotype. Am J Med Genet Part A 158A:2571-2576.

de Moor HM, Costa PT, Terracciano A, Krueger RF, de Geus EJ, Toshiko T, Penninx BW, Esko T, Madden PA, Derringer J, Amin N, Willemsen G., et al. 2012. Meta-analysis of genome-wide association studies for personality. Mol Psychiatry 17:337-349.
Der Kaloustian VM, Russell L, Aradhya S, Richard G, Rosenblatt B, Melançon S. 2011. A de novo 2.1-Mb deletion of 13q12.11 in a child with developmental delay and minor dysmorphic features. Am J Med Genet Part A 155A:2538-2542.

Drummond-Borg M, Kulharya AS, Tonk V, Garcia-Heras J. 2002. Maternal complex chromosome rearrangement ascertained through a del (13) (q12.1q14.1) detected in her mildly affected daughter. Am J Med Genet 107:61-63.

Fang P, Schachner M, Shen YQ. 2012. HMGB1 in development and diseases of the central nervous system. Mol Neurobiol 45:499-506.

Haldeman-Englert CR, Naeem T, Geiger EA, Warnock A, Feret H, Ciano M, Davidson SL, Deardorff MA, Zackai EH, Shaikh TH. 2009. A 781-kb deletion of 13 q12.3 in a patient with Peters plus syndrome. Am J Med Genet Part A 149A:1842-1845.

Lesnik Oberstein SA, Kriek M, White SJ, Kalf ME, Szuhai K, den Dunnen JT, Breuning MH, Hennekam RC. 2006. Peters Plus syndrome is caused by mutations in B3GALTL, a putative glycosyltransferase. Am J Hum Genet 79:562-566.

Lotze MT, Tracey KJ. 2005. High-mobility group box 1 protein (HMGB1): Nuclear weapon in the immune arsenal. Nat Rev Immunol 5: 331-342.

McNally FJ, Vale RD. 1993. Identification of katanin, an ATPase that severs and disassembles stable microtubules. Cell 75:419-429.

Miller DT, Adam MP, Aradhya S, Biesecker LG, Brothman AR, Carter NP, Church DM, Crolla JA, Eichler EE, Epstein CJ, Faucett WA, Feuk L, Friedman JM, Hamosh A, Jackson L, Kaminsky EB, Kok K, Krantz ID, Kuhn RM, Lee C, Ostell JM, Rosenberg C, Scherer SW, Spinner NB, Stavropoulos DJ, Tepperberg JH, Thorland EC, Vermeesch JR, Waggoner DJ, Watson MS, Martin CL, Ledbetter DH. 2010. Consensus statement: chromosomal microarray is a first-tier clinical diagnostic test for individuals with developmental disabilities or congenital anomalies. Am J Hum Genet 86:749-764.

Neale BM, Kou Y, Liu L, Ma'ayan A, Samocha KE, Sabo A, Lin CF, Stevens C, Wang LS, Makarov V, Polak P, Yoon S, et al. 2012. Patterns and rates of exonic de novo mutations in autism spectrum disorders. Nature 485:242-245.

Sanders SJ, Murtha MT, Gupta AR, Murdoch JD, Raubeson MJ, Willsey AJ, Ercan-Sencicek AG, DiLullo NM, Parikshak NN, Stein JL, Walker MF, Ober GT, Teran NA, Song Y, El-Fishawy P, Murtha RC, Choi M, Overton JD, Bjornson RD, Carriero NJ, Meyer KA, Bilguvar K, Mane SM, Sestan N, Lifton RP, Günel M, Roeder K, Geschwind DH, Devlin B, State MW. 2012. De novo mutations revealed by whole-exome sequencing are strongly associated with autism. Nature 485:237-241.

Sharp DJ, Ross JL. 2012. Microtubule-severing enzymes at the cutting edge. J Cell Sci 125:2561-2569.

van Bokhoven H. 2011. Genetic and epigenetic networks in intellectual disabilities. Annu Rev Genet 45:81-104.

Vissers LE, de Vries BB, Veltman JA. 2010. Genomic microarrays in mental retardation: From copy number variation to gene, from research to diagnosis. J Med Genet 47:289-297.

Yu W, Solowska JM, Qiang L, Karabay A, Baird D, Baas PW. 2005. Regulation of microtubule severing by katanin subunits during neuronal development. J Neurosci 25:5573-5583. 